\title{
PREFABRICATED FRACTURED ROCK UNDER STEPWISE LOADING AND UNLOADING
}

\author{
WEI ZHANG \\ State Key Laboratory of Mining Disaster Prevention and Control Co-founded by Shandong Province and the Ministry of \\ Science and Technology, Shandong University of Science and Technology, Qingdao, China, and \\ College of Energy and Mining Engineering, Shandong University of Science and Technology, Qingdao, China \\ TONGBin ZHAO \\ State Key Laboratory of Mining Disaster Prevention and Control Co-founded by Shandong Province and the Ministry of \\ Science and Technology, Shandong University of Science and Technology, Qingdao, China, and \\ College of Energy and Mining Engineering, Shandong University of Science and Technology, Qingdao, China, and \\ National Demonstration Center for Experimental Mining Engineering Education, Shandong University of Science and \\ Technology, Qingdao, China \\ e-mail: 1125671372@qq.com \\ YANCHUN YIN \\ State Key Laboratory of Mining Disaster Prevention and Control Co-founded by Shandong Province and the Ministry of \\ Science and Technology, Shandong University of Science and Technology, Qingdao, China; and \\ College of Energy and Mining Engineering, Shandong University of Science and Technology, Qingdao, China
}

\begin{abstract}
After the engineering rock mass has been affected by comprehensive effects of mining and disturbance, it experiences an input of external energy as well as dissipation and release of internal energy. From the viewpoint of energy, characteristics of rock failure are studied, and the law of rock unstable deformation and energy evolution is analyzed. The damage mechanism of rock is revealed easily. A gradual loading and unloading test of fractured rock is carried out to analyze deformation characteristics of the fractured rock during the load-bearing process, and to study the law of energy dissipation and release under different loading and unloading stress levels. The results show that: (1) the load-bearing time, loading and unloading stress level, stress at crack initiation and peak stress of fractured rock gradually decrease with an increase in the number of cracks, and the descending speed decreases gradually with the increase in the number of cracks; (2) the strain at crack initiation and peak strain of the fractured rock increase gradually with an increase in the number of cracks, and the gathering speed decreases with the increase of the number of cracks; (3) the released strain energy and dissipation energy of fractured rock increase with an increase of loading and unloading stress levels, and the increasing rate gradually slows down; (4) the number of acoustic emission events is positively related to the degree of rock damage, and the increase in the number of cracks will prolong duration of the number of acoustic emission events. The results have a theoretical value for energy evolution and deformation damage of fractured rock masses, and also provide experimental experience to study the instability precursor information of rock materials from the viewpoint of energy.
\end{abstract}

Keywords: fractured rock; graded loading and unloading; rock deformation; energy evolution; acoustic emission

\section{Introduction}

With the increasing number and scale of mining, water conservancy and transportation projects, the issues involved in rock mechanics are becoming more and more complex. The important factor is that there is a large number of different structures in engineering rock masses such 
as weak surfaces. The damaged rock mass containing weak surfaces is generally defined as the fractured rock mass (Li et al., 2020; Cerfontaine and Collin, 2018; Gui et al., 2015). The original rock is affected by mining, causing the stress to redistribute, and stress concentration in weak load-bearing parts such as the end of the rock fissure which is prone to crack. In addition, in the construction of rock mass, cyclic loading is possibly encountered, which has an important impact on the long-term stability of the rock mass (Zhao et al., 2018, 2020; Yang et al., 2021; Qin et al., 2019). Acoustic emission, as an effective technique for studying the internal damage of the rock, can predict stability of the engineering rock mass, which has attracted many scholars to carry out related examination (Indraratna et al., 2015; Chen et al., 2019; Cao et al., 2018).

In recent years, Zhang et al. (2020) found that the number of cycles to fracture of red sandstone under cyclic loading is closely related to the loading frequency and stress amplitude. Liu et al. (2018) conducted an axial cyclic loading and unloading test of salt rock and found that the acoustic emission signal increased with the increase of confining pressure and then weakened. Liu et al. (2020) studied the evolution of elastic modulus and acoustic emission characteristics of marble under uniaxial cyclic loading and unloading conditions. Song et al. (2019) found that a unidirectional cyclic loading and unloading exhibited the effect of strengthening firstly and then weakening. $\mathrm{Xu}$ et al. (2020) studied the strength envelope of deep granite under cyclic loading and unloading conditions and analyzed its failure mechanism. Through the above research, the properties of rock under typical conditions or fatigue properties and acoustic emission characteristics of rocks under cyclic loading and unloading conditions were mainly obtained.

The study of energy change on rock failure has a strong engineering and theoretical value (Yang et al., 2015a; Yang et al., 2015b; Huang et al., 2016). The study of the mechanical response of rock from the viewpoint of energy has attracted widespread attention in the field of rock mechanics and engineering, and has achieved fruitful results. The current research on rock energy is mainly divided into two aspects: one is the study on the total energy before or after the peak of uniaxial or axial loading of rock, so as to establish the constitutive model of rock energy. And the second is to study the fatigue damage and hysteresis effects of rock according to the energy evolution law of rocks under uniaxial or axial periodic loads (Cao et al., 2016; Li et al., 2017b; Li et al., 2019). Regarding the study of uniaxial or axial compression tests in terms of energy, Li et al. (2017a) analyzed the energy changes in the process of rock deformation and the internal relationship of rock strength. Huang and Yang (2018) proposed a new basis for judging the energy of rock-burst based on the perspective of energy dissipation and release. The calculation result was consistent with the actual situation. Huang et al. (2019) studied the energy dissipative elastic damage and its application in engineering. Using the dissipated energy irreversibly derives the equivalent strain and damage yield criterion of elastic damage and establishes an energy-related elastic damage model. Rajeev and Kodikara (2011) conducted uniaxial compression cyclic loading and unloading tests on fine sandstone and silt mudstone. The results showed that the energy dissipation decreased with an increase of rock density.

Based on the above studies, it can be seen that the energy analysis of the uniaxial progressive loading and unloading process is helpful to explore the energy evolution trend and energy distribution of rock in the compaction stage, the elastic and plastic stage, especially the energy evolution law in the fracture process of the fractured rock. In this paper, by carrying out uniaxial progressive loading and unloading tests of prefabricated fractured sandstone, the stress-strain characteristics of the fractured rock peak stress and strain, crack initiation stress and strain, elastic modulus and residual strain are analyzed according to test results corresponding to different conditions of cracks. Considering the effect and influence of different number of cracks, the evolution of elastic release energy, dissipated energy, and crack initiation strain energy with increasing loading and unloading stress levels is analyzed. The number of 
different types of energy and the number of ringing during the gradual loading and unloading process is examined as well. Changes in characteristics of acoustic emission monitoring parameters such as AE energy rate, and in energy correlation characteristics between the released and dissipated energy and the acoustic emission parameters of fractured rock instability are also studied.

\section{Test conditions and scheme}

\subsection{Specimen production}

In the uniaxial progressive loading and unloading test of fractured rock, in order to facilitate the prefabrication of cracks, while taking into account the requirements and rationality of the digital speckle test, the size of specimens is $120 \mathrm{~mm}$ (height) $\times 80 \mathrm{~mm}$ (width) $\times 30 \mathrm{~mm}$ (thickness). The prefabricated cracks have the same length and angle but different numbers (length is $30 \mathrm{~mm}$, width is $2 \mathrm{~mm}$, and the angle is $\left.45^{\circ}\right)$. The overall design is shown in Fig. 1 . In the test, prefabricated cracks were used to characterize the structural planes, and the specimen as a whole was characterized as a rock mass with several structural planes.
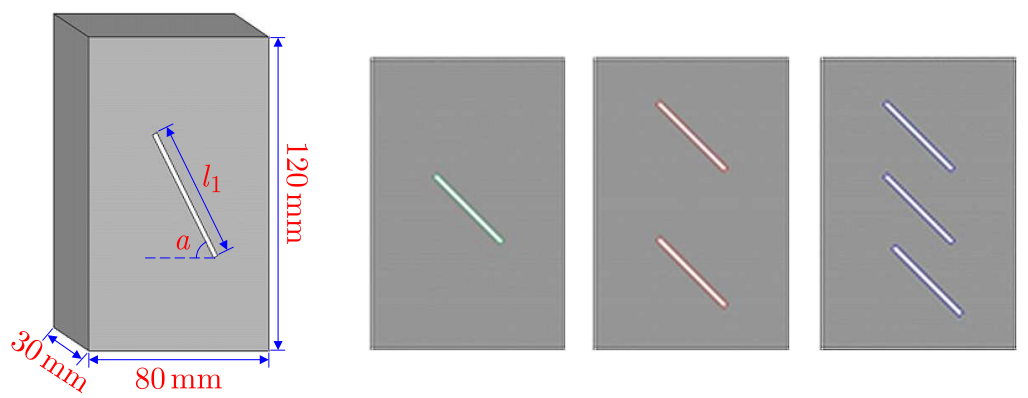

Fig. 1. Dimension drawing of specimen

The specimen used in this test is taken from a complete green sandstone slab with a thickness of $30 \mathrm{~mm}$. When preparing the specimen, a cutting machine is used to cut the green sandstone into rock blocks of the size required for the test, and then the design of cracks is imported into Auto CAD. Then a high-pressure water jet is used to process the prefabricated cracks along the designed path. The specific process is shown in Fig. 2. The machining accuracy of the specimen meets the following requirements: the parallelism deviation of the upper and lower ends of the specimen shall not exceed $0.005 \mathrm{~cm}$; the deviation of thickness and width of the specimen shall not exceed $0.03 \mathrm{~cm}$; the left and right end faces of the specimen shall be perpendicular to the horizontal axis of the specimen. The density of the complete specimen measured by the indoor test is $3.01 \mathrm{~g} / \mathrm{cm}^{3}$, and the uniaxial compressive strength is $92.2 \mathrm{MPa}$.
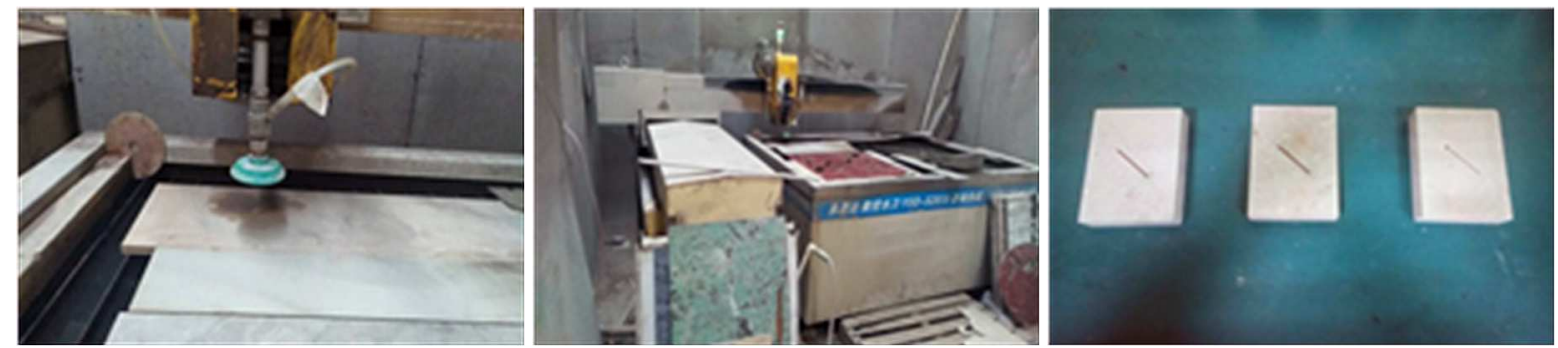

Fig. 2. Production process of the specimen 


\subsection{Test plan and monitoring equipment}

The test was completed in the Rock Mechanics Laboratory of Shandong University of Science and Technology. The computer-controlled RLJW-2000 rock servo pressure testing machine to apply axial pressure through the loading system was used. The loading rate is $0.05 \mathrm{~mm} / \mathrm{min}$. The specific plan for stepwise loading and unloading is: after increasing the load by $10 \% \sigma_{c}$, the first unloading is performed ( $\sigma_{c}$ is the uniaxial compressive strength corresponding to the complete green sandstone of the same size and shape), i.e. unloading down to $0-0.1 \% \sigma_{c}$. Then there is a continuous increase in the magnitude, and at a growth by $20 \% \sigma_{c}$, the second unloading takes place, and at $30 \% \sigma_{c}$ there is a third unloading until the specimen is loaded to failure. As shown in Fig. 3, a loading-displacement curve is recorded during the test, and the acoustic emission is used to monitor energy characteristics of the specimen during the instability and failure process in order to ensure that all data collection starts and ends at the same time.

(a)

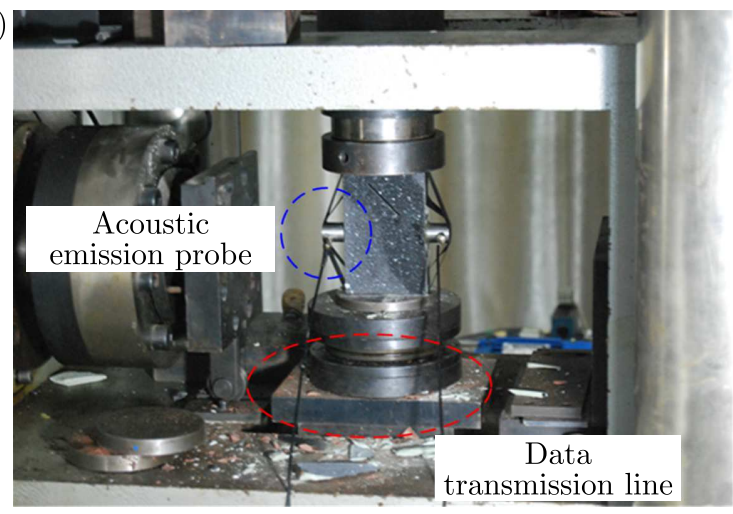

(b)

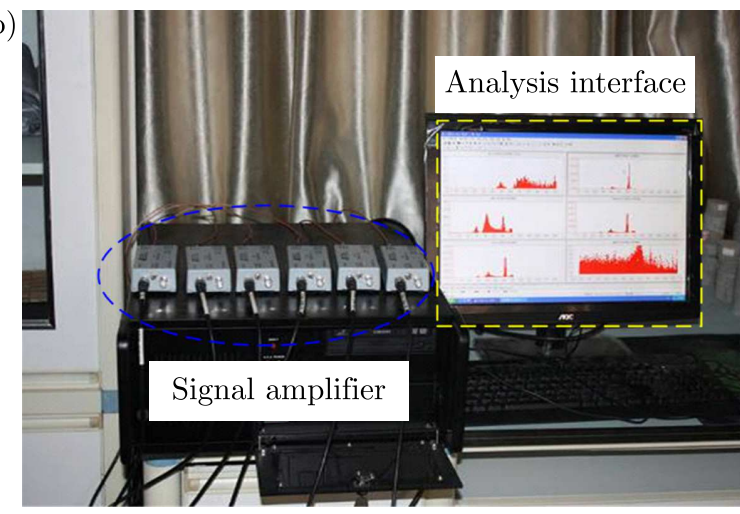

Fig. 3. Acoustic emission equipment: (a) reception, (b) data processing

During the loading and unloading test, acoustic emission is used to obtain the actual measured value of the rock instability failure energy signal and to monitor the initiation and propagation of cracks. An acoustic emission probe is arranged on the left and right sides of the specimen. When the elastic wave emitted by the acoustic emission source reaches the rock surface, it causes a physical signal that can be detected by an acoustic emission sensor. The probe wire converts mechanical vibration of the material into an electrical signal. After being amplified by a pre-signal amplifier, it enters the acoustic emission analysis host for recording and processing. The acoustic emission detector adopts the AE WIN-PCI2 system of American Physical Acoustics Company, which can digitally filter the main AE characteristic parameters such as the rise time, peak count, energy, duration and amplitude of each acquisition channel. During the test, through application pf the equipment band-pass filter, front-end filter and waveform front-end filter functions as well as a selection of settings of PDT, HDT, HLP, the floating threshold setting and intelligent threshold, the removal of noise signals and active collection of interested AE signals are increased.

\section{Analysis of rock deformation and stress-strain curve}

\subsection{Single-cracked rock}

From the axial stress-strain curve in Fig. 4, it can be found that as the loading and unloading stress level increases, the overlap of loading and unloading curves decreases, and the area of the hysteresis ring gradually increases, that is, the unrecoverable plastic deformation increases as well. The loading time $t_{1}$ of the single-cracked rock is about $1850 \mathrm{~s}$, the number of cycles $n_{1}$ is 9 times on average, the peak stress $\sigma_{\max 1}$ is $78.84 \mathrm{MPa}$, and the peak strain $\varepsilon_{\max 1}$ is $1.34 \%$. The 
initiation stress $\sigma_{1}$ of the single-cracked rock is $31.55 \mathrm{MPa}$, reaching $38.3 \%$ of the peak stress. The initiation strain $\varepsilon_{1}$ is $0.28 \%$, reaching $18.8 \%$ of the peak strain.
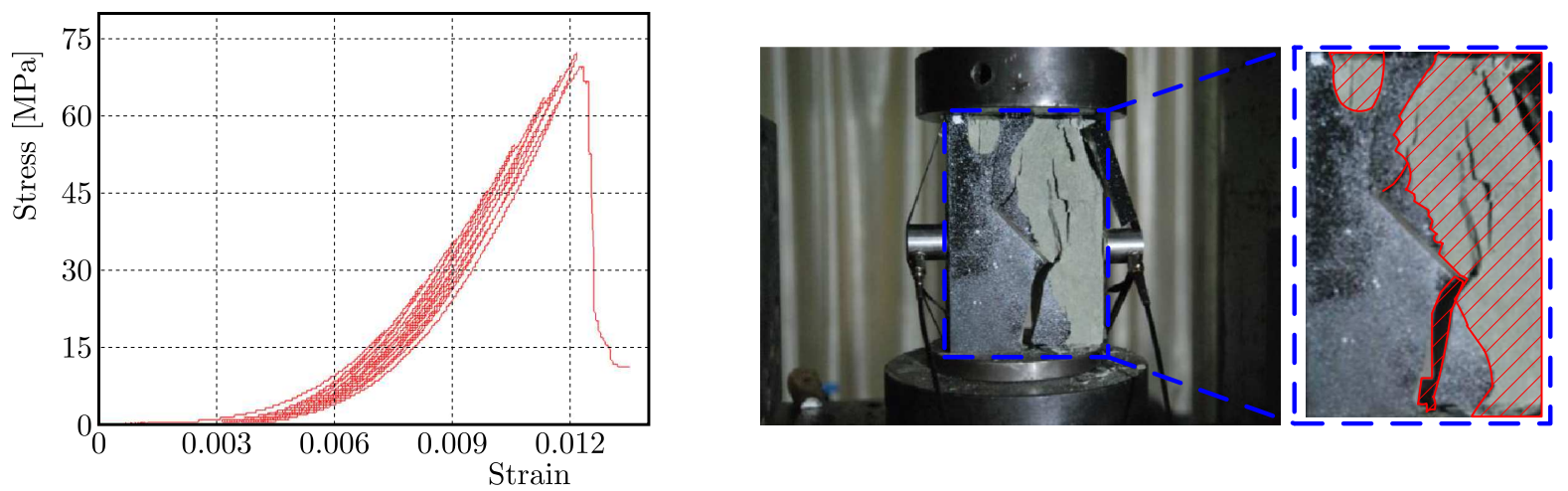

Fig. 4. Stress-strain curve and failure mode

A change in the elastic modulus can indirectly reflect strength characteristics of fractured rocks. Analysis of the elastic modulus is helpful for an in-depth study of the instability and failure laws of fractured rocks. As shown in Fig. 5a, the calculation results of the elastic modulus under the same stress level will obviously occur with the selection of different loading and unloading straight sections. Therefore, the loading and unloading section and the secant line are used to calculate the elastic modulus and make a comparative analysis.

(a)

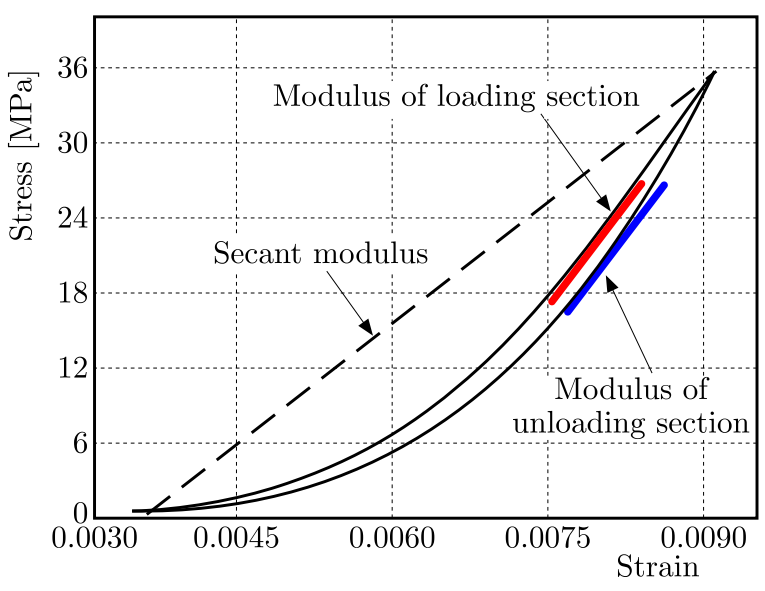

(b)

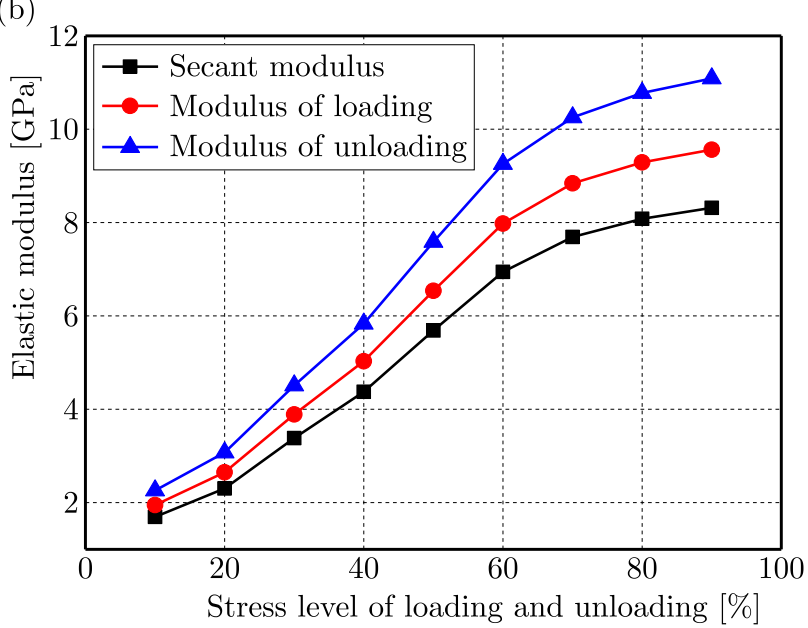

Fig. 5. Elastic modulus of single-cracked rock: (a) rock modulus calculation curve, (b) elastic modulus evolution curve

From Fig. 5b, it can be found that the unloading modulus of the single-cracked rock during the whole loading and unloading process is higher than the loading modulus and the secant modulus, and all the three types of elastic moduli show a growth of the slow-fast-slow rate of change. When the loading and unloading stress level is $10 \%-20 \%$, the growth rate of the three types of elastic moduli is basically the same. When the stress level is $20 \%-50 \%$, the difference of the three types of elastic moduli gradually expands, and the unloading modulus has the highest rate. When entering the $90 \%$ stress level, the three types of elastic moduli reach the peak value, and the difference between these values also reaches the maximum. 


\subsection{Double-cracked rock}

Based on the analysis of the whole failure process of the double-cracked rock, the loading time $t_{2}$ of the double-cracked rock is about $1650 \mathrm{~s}$, the number of cycles $n_{2}$ is 8 on average, the peak stress $\sigma_{\max 2}$ is $66.37 \mathrm{MPa}$, and the peak strain $\varepsilon_{\max 2}$ is $1.88 \%$. The initiation stress $\sigma_{2}$ of the double-cracked rock is $25.32 \mathrm{MPa}$, reaching $37.74 \%$ of the peak stress. The initiation strain $\varepsilon_{2}$ is $0.37 \%$, reaching $20.1 \%$ of the peak strain.
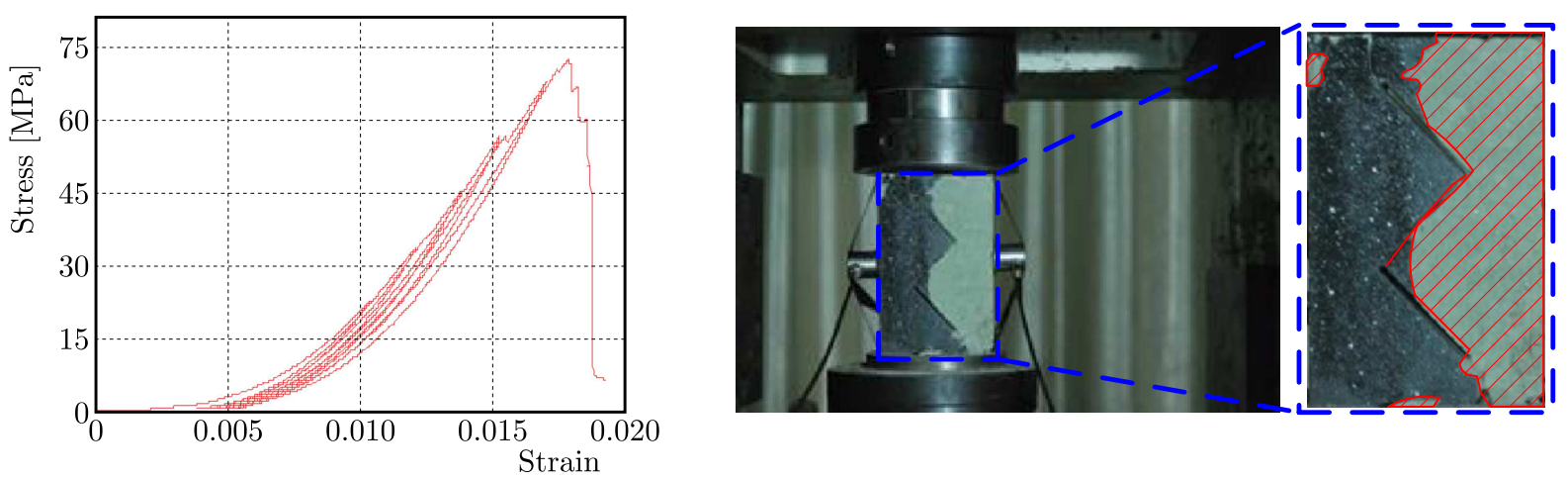

Fig. 6. Stress-strain curve and failure mode

The relationship between the calculated elastic modulus of the double-cracked rock and the loading and unloading stress level is shown in Fig. 7. The changing trends of the three types of elastic moduli in the whole loading and unloading process are basically the same. They all show a growth in the slow-fast-slow rate with an increase in the number of loadings and unloadings. Among them, the unloading modulus is the largest, the loading modulus is the second, and the secant modulus is the smallest. The growth rate of the three types of elastic moduli increases at $30 \%$ of the loading and unloading stress level and continues up to $60 \%$ of the stress level, after which the rate of change slows down until reaching the peak of the elastic modulus, where the unloading modulus has the largest rate of change.

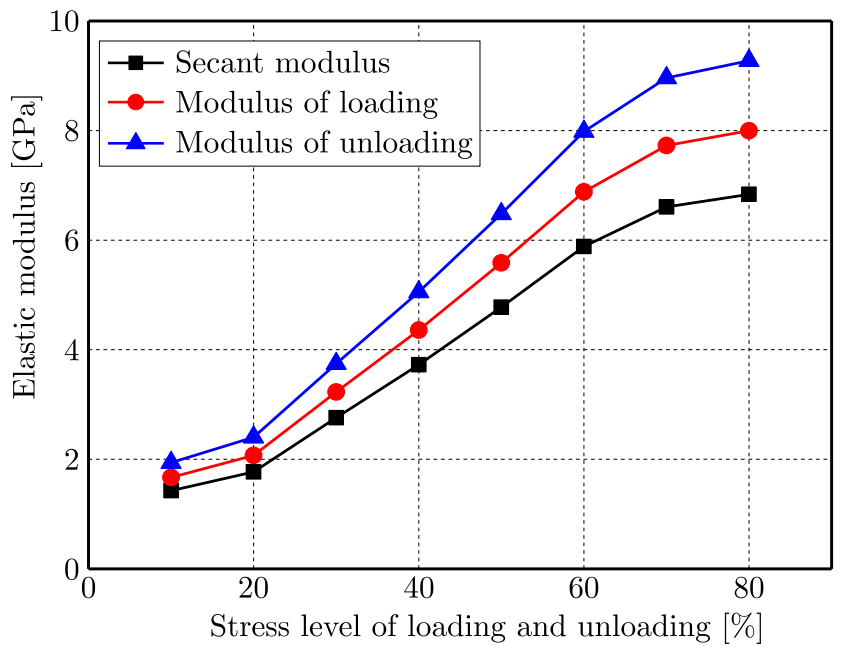

Fig. 7. Elastic modulus of double-cracked rock

\subsection{Triple-cracked rock}

Through the analysis of the whole failure process of the triple-cracked rock, the loading time $t_{3}$ of the triple-cracked rock is about $1450 \mathrm{~s}$, the number of cycles $n_{3}$ is 7 on average, the peak stress $\sigma_{\max 3}$ is $59.98 \mathrm{MPa}$, and the peak strain $\varepsilon_{\max 3}$ is $2.48 \%$. The initiation stress $\sigma_{3}$ of 
the triple-cracked rock is $23.98 \mathrm{MPa}$, reaching $36.66 \%$ of the peak stress. The initiation strain $\varepsilon_{3}$ is $0.62 \%$, reaching $25.9 \%$ of the peak strain.
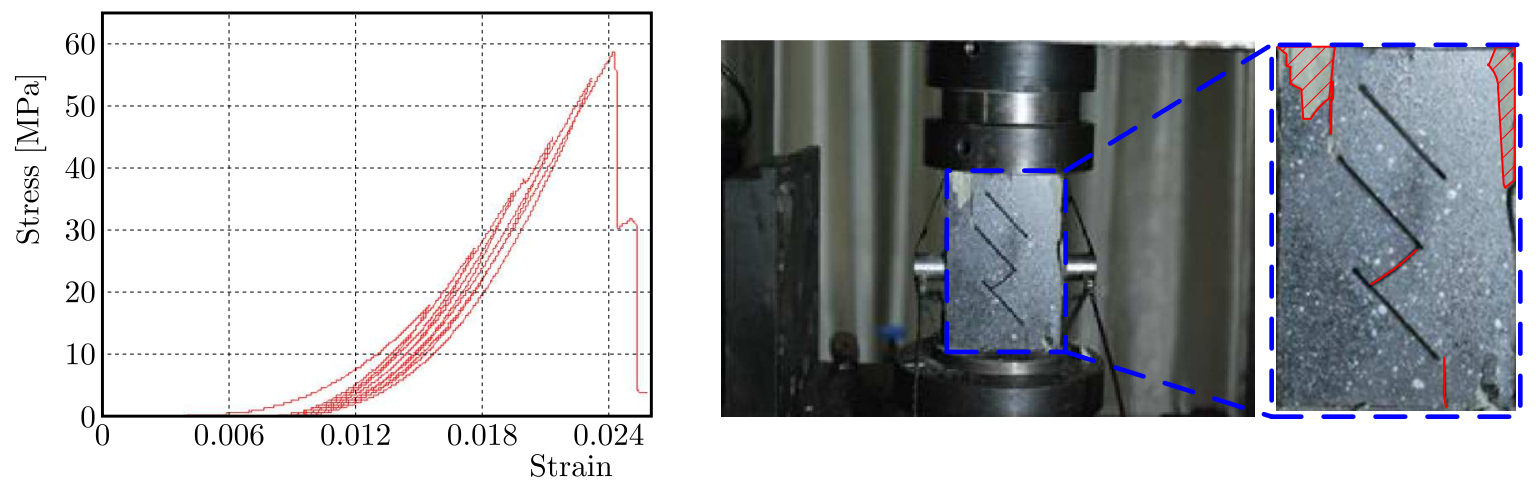

Fig. 8. Stress-strain curve and failure mode

It can be found from Fig. 9 that the three types of elastic moduli have the same changing trend, which is positively correlated with the progressive loading and unloading stress levels. Among them, the unloading modulus is the largest, the loading modulus is the second, and the secant modulus is the smallest. The three types of elastic moduli all slowly increase at the initial stage of loading and unloading. When reaching $30 \%$ of the loading and unloading stress level, the elastic modulus increases rapidly and continues its growth up to $80 \%$ of the loading and unloading stress level, and then the growth rate slows down until it reaches the peak of the elastic modulus.

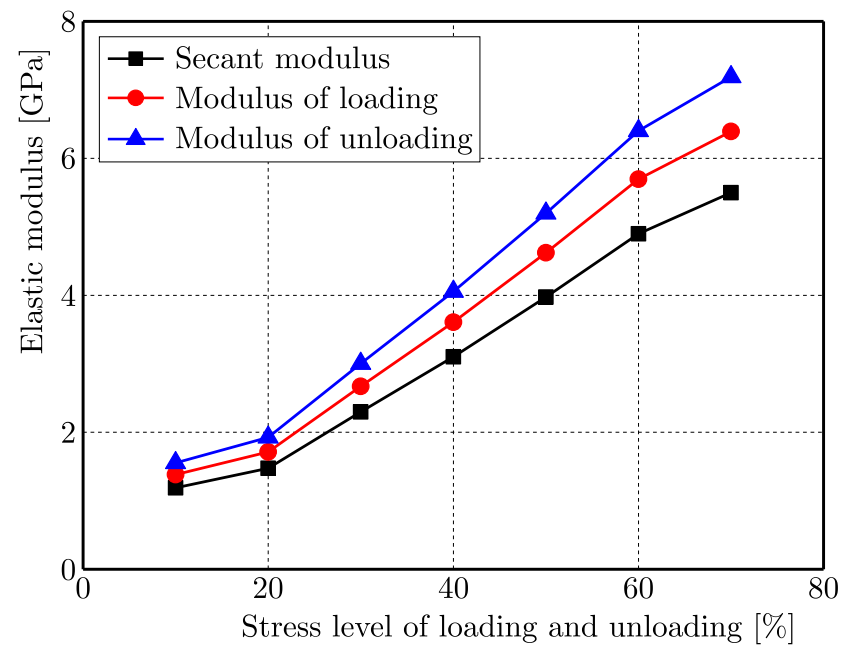

Fig. 9. Elastic modulus of triple-cracked rock

\section{Energy evolution of fractured rock}

The energy conversion of rock from deformation to failure and instability is a dynamic process covering input, accumulation, dissipation and release of the energy. It is represented by external energy, strain energy, dissipation energy, etc. The energy input from the outside is generally mechanical energy, a part of which is stored in rock in the form of reversible elastic strain energy which can be released when unloaded. The other part is dissipated in the form of irreversible frictional heat energy, damage deformation energy, etc. It is impractical to accurately monitor the real-time evolution of each type of energy in laboratory tests and the respective effects of 
releasable strain and dissipated energy on rock damage and destruction. This article only deals with the release of strain and dissipated energy during rock deformation and failure. Establish the energy expression according to the law of conservation of energy

$$
U=U_{1}+U_{2}
$$

In formula (4.1), $U$ is the input energy, the work done by the external loading. $U_{1}$ is the releasable strain energy stored in the rock. $U_{2}$ is the dissipated energy of the rock during the loading process, which is mainly used for damage and plastic deformation.

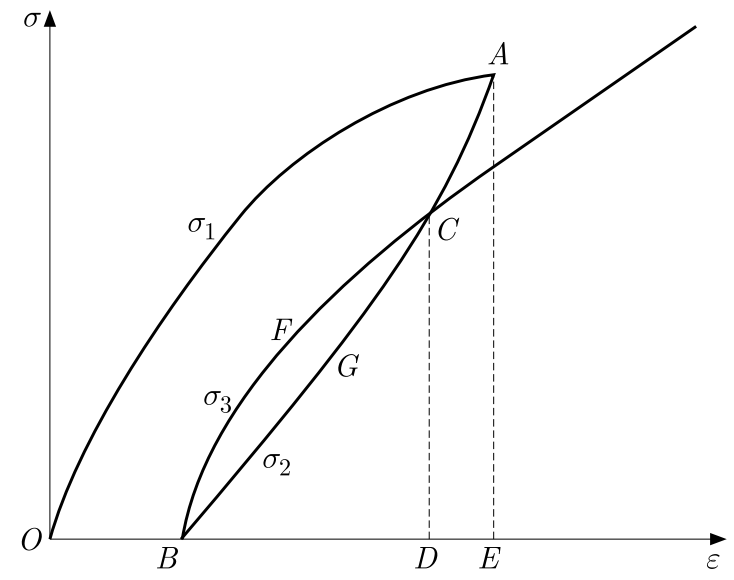

Fig. 10. Schematic diagram of the stress-strain relationship of progressive loading and unloading

(Cao et al., 2018)

In the test, the load-unloading stress-strain curve of the rock is used to calculate the releasable strain energy and the dissipated energy. Figure 10 shows the loading and unloading stress-strain curve. When loaded to the stress level $\sigma$, the elastic release energy density stored in the direction of stress can be determined by the area between the unloading curve and the abscissa. The dissipated energy density can be determined by the area between the loading and unloading curves at the stress-strain point

$$
\begin{aligned}
& W_{O A E(n)}=\int_{O}^{A} \sigma_{1} d \varepsilon \quad W_{B A E(n)}=\int_{B}^{A} \sigma_{2} d \varepsilon \\
& W_{O A B(n)}=W_{O A E(n)}-W_{B A E(n)}=\int_{O}^{A} \sigma_{1} d \varepsilon-\int_{B}^{A} \sigma_{2} d \varepsilon \\
& W_{B F C D(n+1)}=\int_{B}^{C} \sigma_{3} d \varepsilon \quad W_{B G C D(n+1)}=\int_{B}^{C} \sigma_{2} d \varepsilon \\
& W_{B F C G B(n+1)}=W_{B F C D(n+1)}-W_{B G C D(n+1)}=\int_{B}^{C} \sigma_{3} d \varepsilon-\int_{B}^{C} \sigma_{2} d \varepsilon
\end{aligned}
$$

In formulas (4.2), $W_{O A E(n)}$ is the total strain energy accumulated during the $n$-th loading, $W_{B A E(n)}$ is the elastic energy released during the $n$-th unloading, and $W_{O A B(n)}$ is the $n$-th loading and energy dissipated during unloading, $W_{B F C D(n+1)}$ is the total strain energy stored in the $(n+1)$-th load, $W_{B G C D(n)}$ is the elastic energy released during the $n$-th unloading, and $W_{B F C G B(n+1)}$ is the $(n+1)$-th load dissipated energy enclosed by the loading curve and the $n$-th unloading curve. 


\subsection{Single-cracked rock}

Under the condition of gradual loading and unloading, the release of strain and dissipation energy of a single-cracked rock grows with an increase of the loading and unloading stress level. When the stress level increases from $80 \%$ to $90 \%$ near failure, the increase level of the two energies changes. The change is that the increase level of dissipated energy is higher than that of released energy, which shows that the increase level of the dissipated energy is $18.15 \%$, while the increase level of releasable strain energy is only $8.25 \%$.

(a)

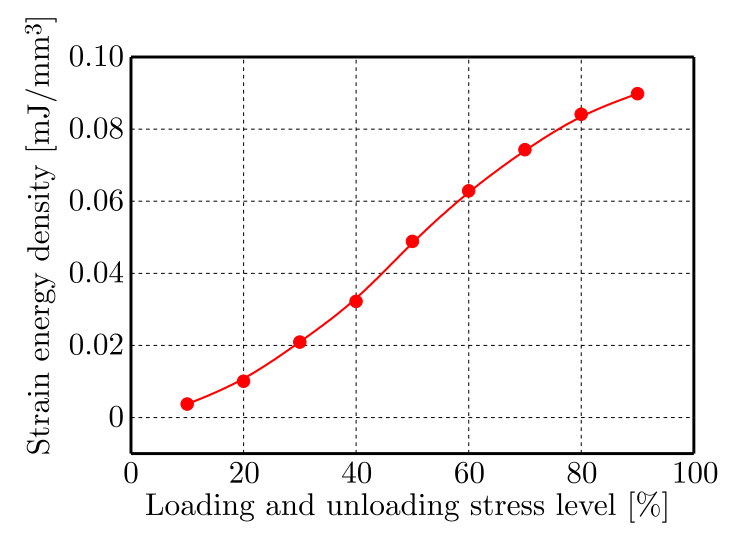

(b)

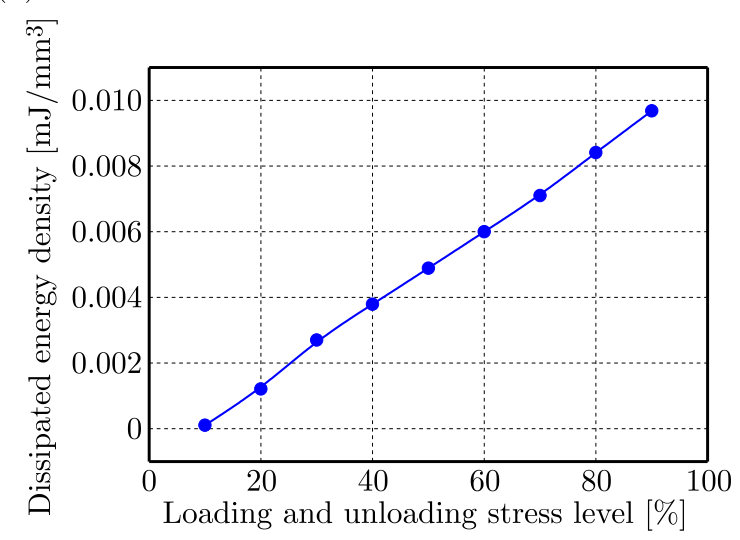

(c)

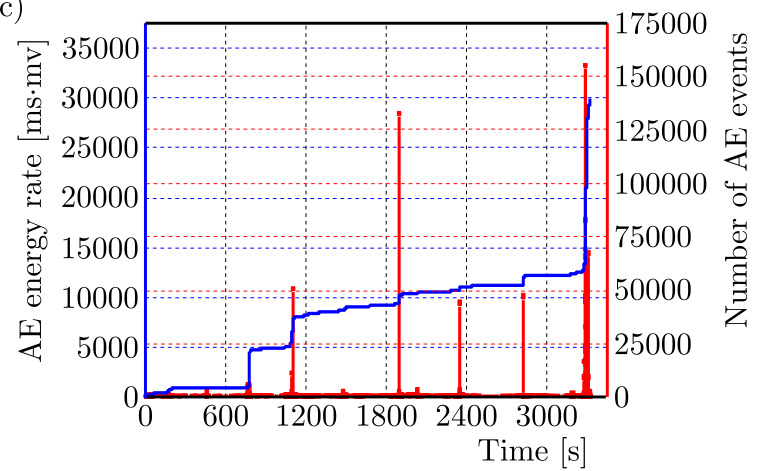

Fig. 11. Energy relationship curve of single-cracked rock: (a) strain energy density and stress level,

(b) dissipated energy density and stress level, (c) curve of AE energy rate and the number of $\mathrm{AE}$ events vs. loading time

Figure 11c shows the corresponding relationship between AE energy rate and the number of $\mathrm{AE}$ events vs. time of the single-cracked rock. The number of $\mathrm{AE}$ events at the beginning of loading is relatively small, indicating that the degree of rock damage is relatively negligible. With gradual loading and unloading, the AE energy rate experiences a stepped growth, indicating that the impact of the loading and unloading on the single-cracked rock gradually increases, and the number of AE events grows significantly when the AE energy rate suddenly increases. When the fractured rock reaches the peak load and destabilizes and fails, the crack propagates rapidly and releases a large amount of energy, which makes the AE energy rate and the number of events significantly increase and reach the maximum value.

\subsection{Double-cracked rock}

Both the releasable strain energy and the dissipated energy of the double-cracked rock increase with an increase of the loading and unloading stress level. When the stress level is loaded from $70 \%$ to $80 \%$ near failure, the dissipated energy increment is $22.25 \%$, and the releasable 
strain energy increment is $12.11 \%$. The releasable strain eergy of the double-cracked rock is basically the same as that of the single-cracked rock. Compared with the single-cracked rock, the dissipated energy is reduced by $18.98 \%$, indicating that the change rate of the releasable strain energy and the dissipated energy is affected by the number of prefabricated cracks.

(a)

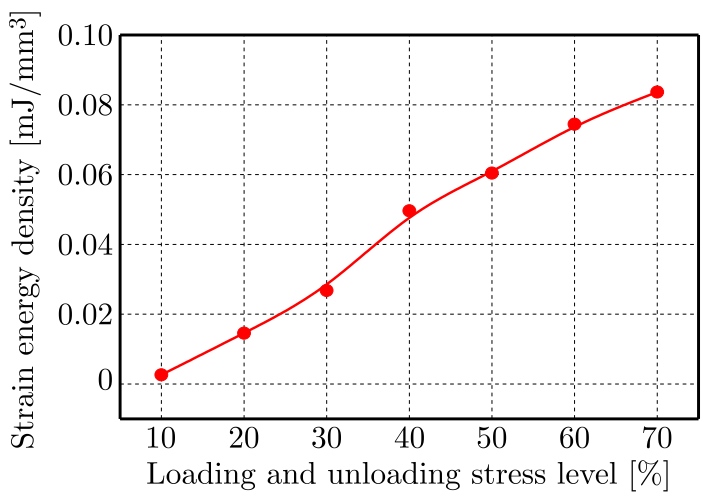

(b)

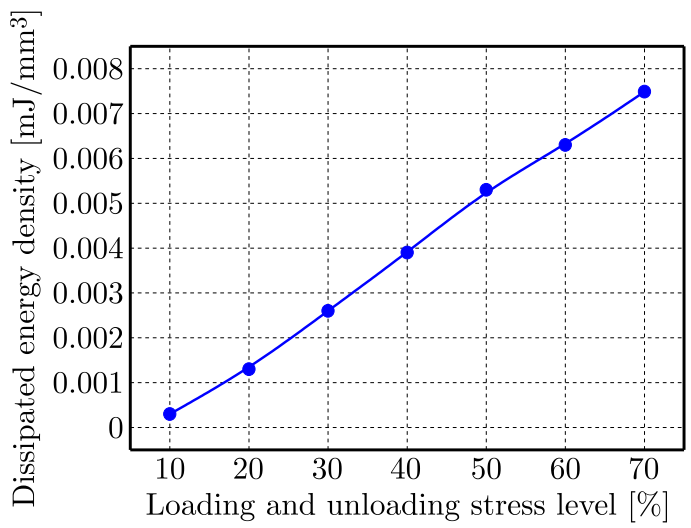

(c)

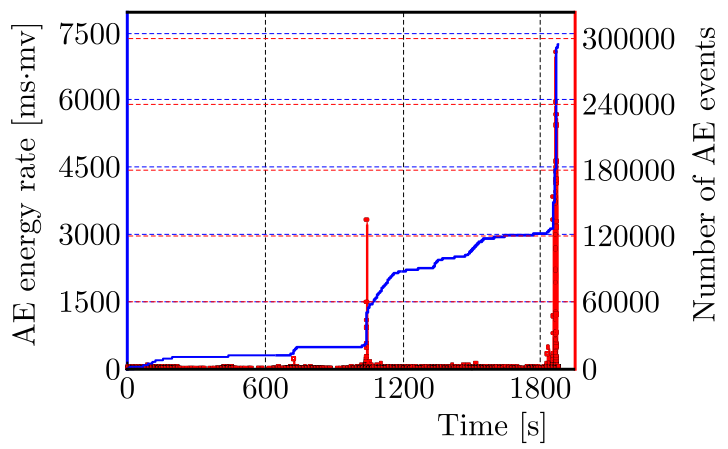

Fig. 12. Energy relationship curve of double-cracked rock: (a) strain energy density and stress level,

(b) dissipated energy density and stress level, (c) curve of AE energy rate and the number of AE events vs. loading time

Figure 12c shows the AE energy rate and the number of AE events versus of the double-cracked rock, which are similar to the acoustic emission characteristics of the single-cracked rock. A large number of acoustic emission counts is generated at the initial stage of loading of the specimen. The AE energy rate experiences a stepped increase, and the number of acoustic emission events and energy rate reach the maximum when the rock is unstable and destroyed. However, the number of acoustic emissions of the double-cracked rock at each stage of the progressive loading and unloading is significantly higher than that of the single-cracked rock. This is because the increase in the number of cracks leads to this experimental phenomenon.

\subsection{Triple-cracked rock}

The curve of energy-loading and unloading stress level of the triple-cracked rock increases linearly, reflecting that the change trend of releasable strain and dissipated energy increasing with growth of the loading and unloading stress level is less affected by the number and location of cracks. When the stress level is loaded from $60 \%$ to $70 \%$ near failure, the growth rate of dissipated energy of the triple-cracked rock is nearly doubled compared to the releasable strain energy. The increment of the dissipated energy is $24.13 \%$, and that of the releasable strain energy is $12.25 \%$. The dissipated energy of the triple-cracked rock is basically the same as that of single- and double-cracked rock, but the releasable strain energy is reduced by $16.92 \%$. With 
an increase of the number of cracks, the rate of change of the releasable strain and dissipated energy of the fractured rock slows down.

(a)

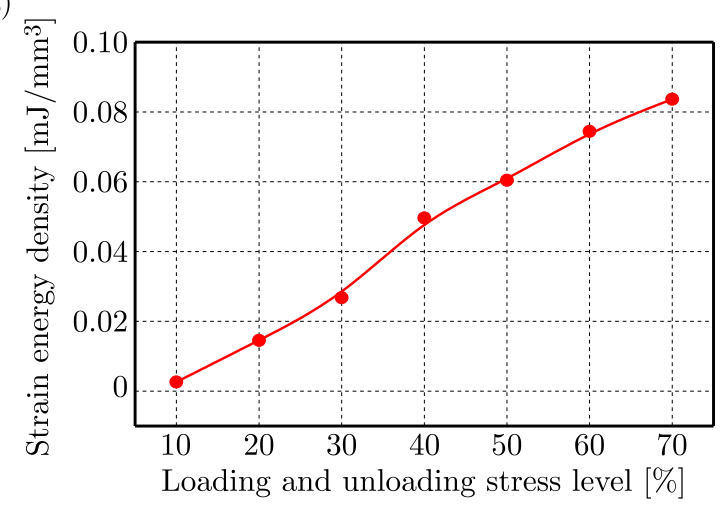

(b)

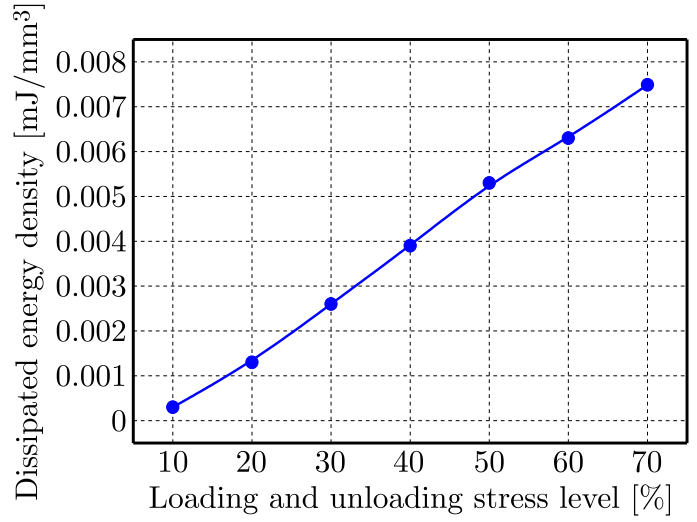

(c)

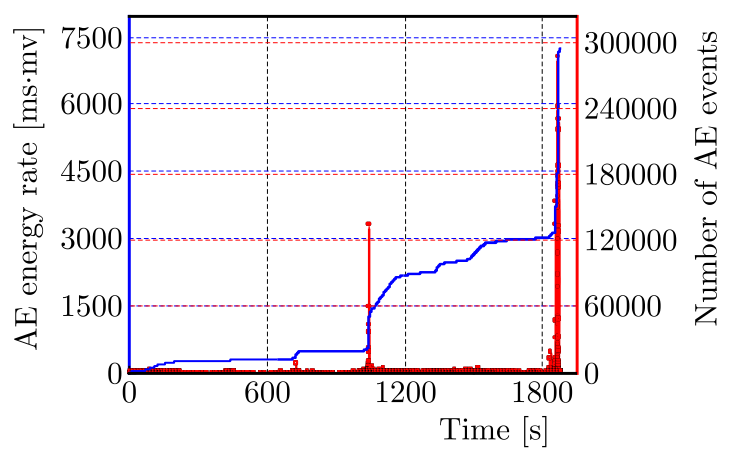

Fig. 13. Energy relationship curve of triple-cracked rock: (a) strain energy density and stress level, (b) dissipated energy density and stress level, (c) curve of AE energy rate and the number of

$\mathrm{AE}$ events vs. loading time

Figure 13c shows the corresponding relationship between the AE energy rate of the triple-cracked rock and the number of AE events versus time. Through the comparative analysis of Figs. 11c and 12c, it can be found that the number of AE events is positively correlated with the degree of rock damage. The triple-cracked rock has the most cracks, and the crack is the most complicated. However, the number of AE events is smaller which does not truly reflect the evolution of the triple-cracked rock cracks, indicating that the number of events represents the failure of the fractured rock.

\section{Conclusion}

- With an increase in the number of prefabricated cracks, the coincidence degree of the loading and unloading curves gradually decreases, and the area of the hysteresis loop gradually increases. The unrecoverable deformation of the fractured rock and its accumulation increases. The brittleness and uniformity of fractured rock decrease with an extension of the plastic time in the stress-strain curve.

- The loading time, loading and unloading stress level and peak stress of fractured rock are negatively correlated with the number of prefabricated cracks, whereas the peak strain is positively correlated with the number of prefabricated cracks.

- The strain energy and dissipation energy can be more intensively released by fractured rock with an increase of the loading and unloading stress level, but the intensification gradually slows down. When approaching failure, the energy increase of fractured rock 
changes significantly. Comparing the change of dissipation energy with that of strain energy a nearly doubled increase is confirmed.

\section{Acknowledgements}

The research described in this paper was financially supported by Major Program of Shandong Provincial Natural Science Foundation (No. ZR2019ZD13) and National Natural Science Foundation of China (No. 51974171).

\section{References}

1. Cao P., Youdao W., Wang Y., Haiping Y., Yuan B., 2018, Study on nonlinear damage creep constitutive model for high-stress soft rock, Environmental Earth Sciences, 75, 10, 902-908

2. Cao R.H., Cao P., Lin H., Pu C.-Z., Ou K., 2016, Mechanical behavior of brittle rock-like specimens with pre-existing fissures under uniaxial loading: experimental studies and particle mechanics approach, Rock Mechanics and Rock Engineering, 49, 3, 763-783

3. Cerfontaine B., Collin F., 2018, Cyclic and fatigue behaviour of rock materials: review, interpretation and research perspectives, Rock Mechanics and Rock Engineering, 51, 2, 391-414

4. Chen S., Yin D., Liu H., Chen B., Jiang N., 2019, Effects of coal's initial macro-cracks on rockburst tendency of rock-coal composite samples, Royal Society Open Science, 6, 11, 181795

5. Gui Y., Bui H.H., Kodikara J., 2015, An application of a cohesive fracture model combining compression, tension and shear in soft rocks, Computers and Geotechnics, 66, 142-157

6. Huang S., NAn Y., Ye Y., Cui X., 2019, Strength and failure characteristics of rocklike material containing a large-opening crack under uniaxial compression: experimental and numerical studies, International Journal of Geomechanics, 19, 8, 1943-5622

7. Huang Y.H., Yang S.Q., Tian W.L., Zeng W., Yu L.Y., 2016, An experimental study on fracture mechanical behavior of rock-like materials containing two unparallel fissures under uniaxial compression, Acta Mechanica Sinica, 32, 3, 442-455

8. Huang Y.H., YANG S.Q., 2018, Mechanical and cracking behavior of granite containing two coplanar flaws under conventional triaxial compression, International Journal of Damage Mechanics, 28, $4,590-610$

9. Indraratna B., Thirukumaran S., Brown E.T., Zhu S.-P., 2015, Modelling the shear behaviour of rock joints with asperity damage under constant normal stiffness, Rock Mechanics and Rock Engineering, 48, 1, 179-195

10. Li D., Han Z., Sun X., Zhou T., Li X., 2019, Dynamic mechanical properties and fracturing behavior of marble specimens containing single and double flaws in SHPB tests, Rock Mechanics and Rock Engineering, 52, 6, 1623-1643

11. Li D., Zhu Q., Zhou Z., Li X., Ranjith P.G., 2017a, Fracture analysis of marble specimens with a hole under uniaxial compression by digital image correlation, Engineering Fracture Mechanics, 183, 9, 109-124

12. Li J., Hong L., Zhou K., Xia C., Zhu L., 2020, Influence of loading rate on the energy evolution characteristics of rocks under cyclic loading and unloading, Energies, 13, 14, 4003

13. Li X.B., Zhou T., Li D.Y., 2017b, Dynamic strength and fracturing behavior of single-flawed prismatic marble specimens under impact loading with a split-Hopkinson pressure bar, Rock Mechanics and Rock Engineering, 50, 1, 29-44

14. Liu D., Shi X., Zhang X., Wang B., Tang T., Han W.H., 2018, Hydraulic fracturing test with prefabricated crack on anisotropic shale: Laboratory testing and numerical simulation, Journal of Petroleum Science and Engineering, 168, 409-418 
15. Liu Q., Sun Y., Li J., 2020, Experimental study on seepage characteristics of Jurassic weakly cemented sandstone under water-rock interaction, Geofluids, 2020, 3, 1-12

16. Rajeev P., Kodikara J., 2011, Numerical analysis of an experimental pipe buried in swelling soil, Computers and Geotechnics, 9, 38, 897-904

17. Song D., You Q., Wang E., Song X., Li Z., Qiu L., Wang S., 2019, Characteristics of EMR emitted by coal and rock with prefabricated cracks under uniaxial compression, Geomechanics and Engineering, 19, 1, 49-60

18. Qin D.D., Wang X.F., Zhang D.S., Chen X., 2019, Study on surrounding rock-bearing structure and associated control mechanism of deep soft rock roadway under dynamic pressure, Sustainability, 11, 7, 1892-1896

19. Xu H., Qin Y., Wang G., Fan C., Wu M., Wang R., 2020, Discrete element study on mesomechanical behavior of crack propagation in coal samples with two prefabricated fissures under biaxial compression, Powder Technology, 375, 42-59

20. Yang S.Q., Tian W.L., Huang Y.H., Ranjith P.G., Ju Y., 2015a, An experimental and numerical study on cracking behavior of brittle sandstone containing two non-coplanar fissures under uniaxial compression, Rock Mechanics and Rock Engineering, 49, 4, 1497-1515

21. Yang X.-X., Kulatilake P.H.S.W., Jing H., YAng S.-Q., 2015b, Numerical simulation of a jointed rock block mechanical behavior adjacent to an underground excavation and comparison with physical model test results, Tunnelling and Underground Space Technology, 50, 129-142

22. Yang X.W., Zhang X.P., Zhang Q., Li C.D., Wang D.J., 2021, Study on the mechanisms of crack turning in bedded rock, Engineering Fracture Mechanics, 247, Paper ID: 107630

23. Zhang S., WAng L., GAO M., 2020, Experimental and numerical study of the influence of prefabricated crack width on the fracture toughness of nscb specimens, Rock Mechanics and Rock Engineering, 53, 5133-5154

24. Zhao T.B., Guo W.Y., Tan Y.L., Yin Y.C., Cai L.S., Pan J.F., 2018, Case studies of rock bursts under complicated geological conditions during multi-seam mining at a depth of $800 \mathrm{~m}$, Rock Mechanics and Rock Engineering, 51, 5, 1539-1564

25. Zhao T.B., Zhang W., Gu S.T., LV Y.W, Li Z.H., 2020, Study on fracture mechanics of granite based on digital speckle correlation method, International Journal of Solids and Structures, 193-194, 192-199 